\title{
Corrigendum
}

\section{A revision of species of the Parmelia saxatilis complex in the Iberian Peninsula with the description of $P$. rojoi, a new potentially relict species - CORRIGENDUM}

\author{
Ana Crespo, Víctor J. Rico, Elisa Garrido, H. Thorsten Lumbsch and Pradeep K. Divakar (D)
}

doi.org/10.1017/S0024282920000341, Published by Cambridge University Press, 11 November 2020.

In the Abstract, a statement referring to the newly described species P. rojoi A. Crespo, V. J. Rico \& Divakar, by Crespo et al. (2020), reads '... and is restricted to higher altitudes of northern and central Spain'. This should be corrected to read 'and is restricted to mild, warm and low altitude localities in the south of the Iberian Peninsula (Spain: Cádiz and Málaga).'

The complete sentence should therefore read: 'The new species, which forms a sister-group relationship with $P$. saxatilis s. str., is rare in the Iberian Peninsula and is restricted to mild, warm and low altitude localities in the south of the Iberian Peninsula (Spain: Cádiz and Málaga).'

Author ORCID. (D) Pradeep Divakar, 0000-0002-0300-0124.

\section{Reference}

Crespo A, Rico VJ, Garrido E, Lumbsch HT and Divakar PK (2020) A revision of species of the Parmelia saxatilis complex in the Iberian Peninsula with the description of $P$. rojoi, a new potentially relict species. Lichenologist, 52, 365-376. 